\title{
Serum potassium, calcium and magnesium in patients receiving ESHAP chemotherapy for relapsed lymphomas
}

\author{
${ }^{1} \mathrm{~J}$ Zekri, ${ }^{2} \mathrm{NLC}$ Cheah, ${ }^{3} \mathrm{~L}$ Evans, ${ }^{4} \mathrm{~B}$ Hancock \\ ${ }^{1}$ Specialist Registrar in Medical Oncology; ${ }^{2}$ Senior House Officer in Oncology; ${ }^{3}$ Consultant Medical Oncologist; ${ }^{4}$ Professor of Medical \\ Oncology, Academic Unit of Clinical Oncology, Cancer Research Centre, Weston Park Hospital, Sheffield, UK
}

ABSTRACT Etoposide, methylprednisolone, cytarabine and cisplatin (ESHAP) is one of the mostly widely used chemotherapy regimens for patients with relapsed lymphomas. Cisplatin administration is commonly associated with electrolyte imbalance. Careful monitoring of renal function and serum electrolytes is therefore essential in this setting.

Aims: To review the practice of electrolyte monitoring - potassium (K), calcium (Ca) and magnesium $(\mathrm{Mg})$ - in patients receiving ESHAP and the frequency and severity of abnormalities and their management.

Methods: Twenty-one consecutive patients received ESHAP. The medical records of 16 patients were retrievable and reviewed retrospectively. Results of serum K, $\mathrm{Ca}$ and $\mathrm{Mg}$ were collected prior to and after cycles I, 2 and 3 of ESHAP, if measured.

Results: Serum K levels prior to every cycle did not show any noticeable change. The means were 4.42, 4.34 and $4.43 \mathrm{mmol} / \mathrm{l}$ before cycles I, 2 and 3, respectively. In one patient hypokalaemia was severe, refractory and symptomatic when preceded by hypomagnesaemia. Serum-adjusted calcium levels showed only minimal reduction. The means were 2.46, 2.40 and $2.38 \mathrm{mmol} / \mathrm{l}$ before cycles I, 2 and 3 respectively. Mean serum $\mathrm{Mg}$ levels prior to every cycle showed progressive reduction; $0.84,0.75$ and $0.67 \mathrm{mmol} / \mathrm{l}$ before cycles I, 2 and 3, respectively. This was associated with a progressive increase in the amount of required $\mathrm{Mg}$ supplementation. Serum K, Ca and $\mathrm{Mg}$ was measured prior to $100 \%, 67 \%$ and $35 \%$ of administered cycles, respectively.

Conclusion: In patients receiving ESHAP, hypokalaemia can occasionally be seen, especially if preceded by hypomagnesaemia. Mild cumulative hypocalcaemia is recognised. Hypomagnesaemia is a progressive complication and physicians need be aware of its importance.

KEYWORDS Cisplatin, ESHAP, hypocalcaemia, hypokalaemia, hypomagnesaemia
Published online December 2009

Correspondence to J Zekri, Department of Oncology, King Faisal Specialist Hospital and Research Centre, PO Box 40047, Jeddah 2 I 499, MBC \# J-64, Kingdom of Saudi Arabia

tel. +96626677777 ext. 4348 e-mail jmzekri@hotmail.com

DECLARATION OF INTERESTS No conflict of interests declared.

\section{INTRODUCTION}

Etoposide, methylprednisolone, cytarabine and cisplatin (ESHAP) is one of the mostly widely used chemotherapy regimens for patients with relapsed lymphomas. The response rate in the first relapse is about $70 \%$, with half of responders achieving complete response. ${ }^{1,2}$ Cisplatin is a particularly effective anti-lymphoma agent in this regimen. The response rate is halved if cisplatin is omitted from the regimen. ${ }^{2}$

Renal toxicity is a common and dose-limiting toxicity of cisplatin. One of the recognised mechanisms of toxicity is renal tubular damage. This is thought to explain the chemical and/or clinical electrolyte imbalance seen. However, recent research indicates that magnesium loss associated with cisplatin treatment may be the result of lowered intestinal absorption. ${ }^{3}$ Profound hypomagnesaemia, hypokalaemia and hypocalcaemia have been reported in patients on cisplatin therapy. ${ }^{4,5}$
Careful monitoring of renal function and serum electrolytes is therefore essential during the administration of cisplatin. ${ }^{6}$

We performed a retrospective review to audit the practice of electrolyte monitoring - potassium (K), calcium ( $\mathrm{Ca}$ ) and magnesium $(\mathrm{Mg})$ - in patients having ESHAP chemotherapy, and documented the frequency and severity of abnormalities and their management.

\section{PATIENTS AND METHODS}

Twenty-one consecutive patients started ESHAP in one calendar year (January-December 2002) for salvage treatment of relapsed lymphomas in a single cancer centre. The regimen comprises etoposide $40 \mathrm{mg} / \mathrm{m}^{2}$ on days $\mathrm{I}-4$, methylprednisolone $500 \mathrm{mg}$ on days I-5, cytarabine $2 \mathrm{~g} / \mathrm{m}^{2}$ on day 5 and cisplatin $25 \mathrm{mg} / \mathrm{m}^{2}$ on days $\mathrm{I}-4$ (repeated every three weeks). Five patients were excluded from this analysis. The records for three of these patients were not 
retrievable, one patient died shortly after cycle I (cause of death not related to electrolyte imbalance) and one patient had the first cycle at another facility.

The medical and electronic records of 16 patients were retrievable, reviewed retrospectively and are the subject of this report. We restricted the analysis to the first three cycles of ESHAP. The baseline electrolytes level was that prior to cycle I. Electrolyte values on day I of subsequent cycles were also collected. Some patients had serum electrolyte measurements between cycles if they had hospital visits for any reason other than administration of chemotherapy. Values at these visits were also captured and labelled as interim levels. The lowest values of $\mathrm{K}, \mathrm{Ca}$ and $\mathrm{Mg}$ in any patient were also captured to reflect the extreme picture and were labelled nadir levels.

Standards for the audit were:

I. Patients on ESHAP had serum electrolytes monitored before every cycle. For the purpose of this audit these included $\mathrm{K}$, adjusted $\mathrm{Ca}$ and $\mathrm{Mg}$.

2. $\mathrm{Mg}$ supplementation should be administered if pretreatment serum level is less than $0.7 \mathrm{mmol} / \mathrm{l}$.

The approval of the hospital's audit department was obtained before data collection. All patients' identifying information was removed from the data prior to review.

This is an observational, retrospective report where no sample frame was specified nor comparator group presented. Statistical comparison was made to isolated baseline measures only and neither type 2 statistical error nor regression-to-mean effects can be ruled out.

\section{RESULTS}

Sixteen patients had one or more cycles of ESHAP. Fifteen had two or more, while 12 had three cycles. In total there were 43 episodes of chemotherapy. The baseline serum urea and creatinine, diuretic use, total cisplatin dose per cycle and regimen dose modification are illustrated in Table I.

\section{Potassium}

Mean serum $\mathrm{K}$ levels prior to every cycle did not show any noticeable change. The means were $4.42,4.34$ and $4.43 \mathrm{mmol} / \mathrm{l}$ before cycles I, 2 and 3, respectively. The interim and lowest $\mathrm{K}$ levels also did not show any change (Figure I). This is reflected in only a minimum requirement for $\mathrm{K}$ supplementation (Figure 2). However, one patient with low baseline $\mathrm{K}$ level (2.8) was admitted 15 days after the third cycle with convulsions and hypokalaemia (2.5). This was preceded by a very low $\mathrm{Mg}$ level $(0.23 \mathrm{mmol} / \mathrm{l})$. The patient required a large amount of $\mathrm{Mg}(192 \mathrm{mmol})$ and $\mathrm{K}$ supplementation of $790 \mathrm{mmol}$ over 17 days (Figure 2). Serum $\mathrm{K}$ was measured prior to all 43 administered cycles.
TABLE I Baseline serum urea and creatinine, diuretic use, total cisplatin dose per cycle and regimen dose modification

\begin{tabular}{|l|l|l|l|}
\hline & Cycle I & Cycle 2 & Cycle 3 \\
\hline Number of patients & 16 & $\mathrm{I} 5$ & $\mathrm{I} 2$ \\
\hline Dose reduction & $\begin{array}{l}2 \text { patients } \\
(20 \%, 50 \%)\end{array}$ & $\begin{array}{l}2 \text { patients } \\
(20 \% \times 2)\end{array}$ & $\begin{array}{l}3 \text { patients } \\
(20 \% \times 3)\end{array}$ \\
\hline $\begin{array}{l}\text { Mean cisplatin dose } \\
\text { per cycle }\end{array}$ & $175 \mathrm{mg}$ & $175.5 \mathrm{mg}$ & $157.7 \mathrm{mg}$ \\
\hline Oral diuretics & 2 & 0 & 0 \\
\hline Frusemide & $\mathrm{I}$ & $\mathrm{I}$ & 0 \\
\hline Bendrofluazide & $\mathrm{I}$ & $\mathrm{I}$ & $\mathrm{I}$ \\
\hline Other & 4.74 & 3.99 & 4.62 \\
\hline $\begin{array}{l}\text { Mean serum urea } \\
\text { Normal (2-6.2 mmol//) }\end{array}$ & 78.7 & $75 . \mathrm{I}$ & 76.2 \\
\hline $\begin{array}{l}\text { Mean serum } \\
\text { creatinine } \\
\text { Normal (62-120 umol/l) }\end{array}$ & & & \\
\hline
\end{tabular}

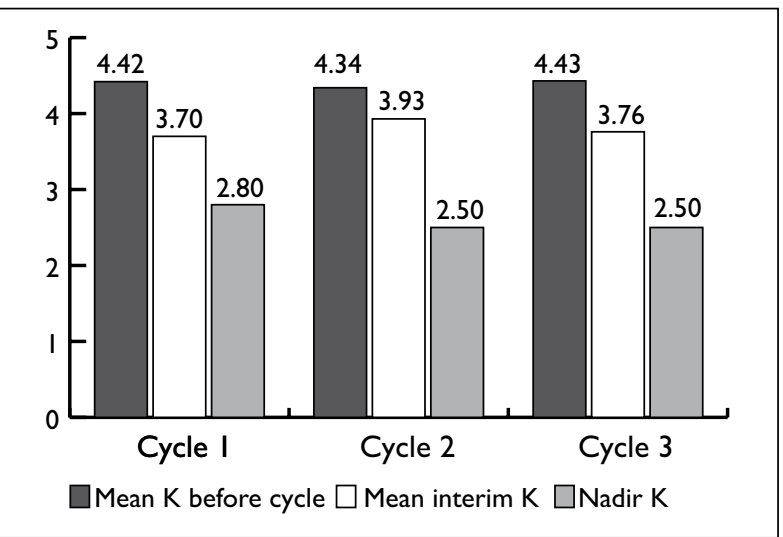

FIGURE I Pre-treatment, interim and nadir K levels (mmol/l)

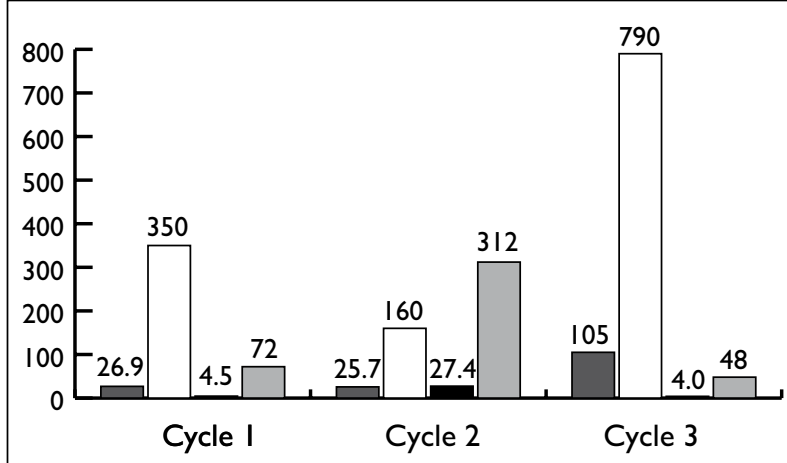

$\square$ Mean IV K $\square$ Largest IV K $\square$ Mean oral K $\square$ Largest oral K

FIGURE 2 Administered $\mathrm{K}$ supplementation (mmol) after each ESHAP cycle

\section{Calcium}

Mean serum albumin-adjusted calcium levels showed only minimal reduction over sequential cycles. The means were $2.46,2.40$ and $2.38 \mathrm{mmol} / \mathrm{L}$ before cycles I, 2 and 3 , respectively. The interim levels did not show any relevant changes (Figure 3). Overall, there was only a minimum requirement for $\mathrm{Ca}$ supplementation. The 


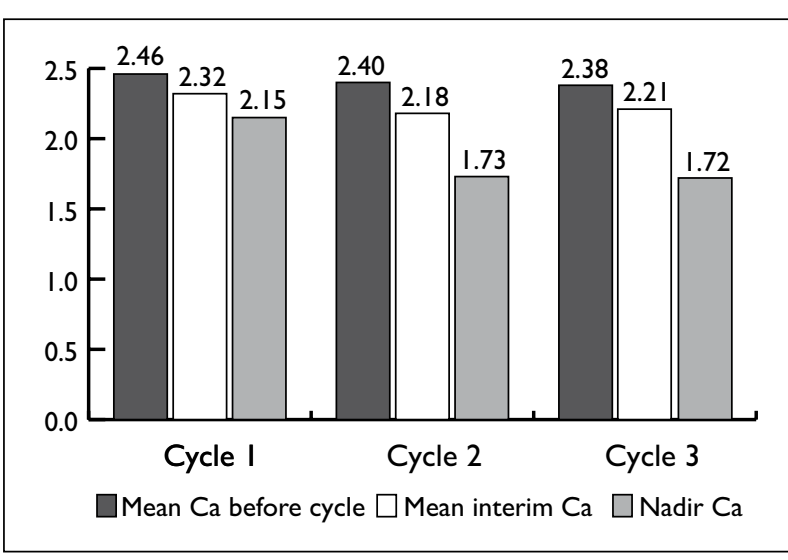

FIGURE 3 Pre-treatment, interim and nadir Ca levels (mmol/l)

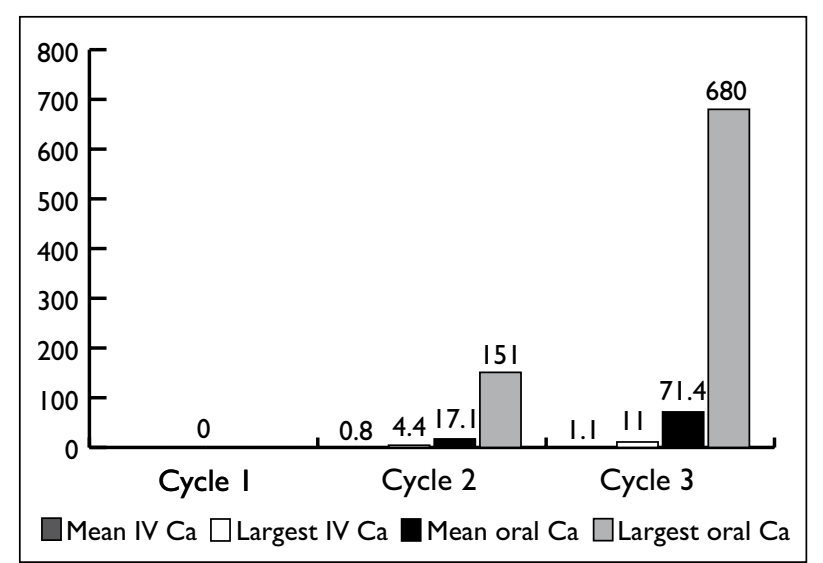

FIGURE 4 Administered Ca supplementation ( $\mathrm{mmol}$ ) after each ESHAP cycle

lowest baseline $\mathrm{Ca}$ level in one patient was 2.15, i.e. below normal range $(2.2-2.6 \mathrm{mmol} / \mathrm{l})$ and fell further (Figure 3). This patient required a relatively large amount of Ca supplementation after the second and third cycles of chemotherapy (Figure 4). Serum Ca was measured prior to $29 / 43(67 \%)$ of the administered cycles.

\section{Magnesium}

Mean serum $\mathrm{Mg}$ levels prior to every cycle showed sequential reduction. The means were $0.84,0.75$ and $0.67 \mathrm{mmol} / \mathrm{l}$ before cycles I, 2 and 3, respectively. The interim levels showed obvious progressive decline (Figure 5). The lowest levels were very low: 0.5, 0.17 and $0.23 \mathrm{mmol} / \mathrm{l}$ after cycles I, 2 and 3, respectively. There was a progressive increase in the amount of required $\mathrm{Mg}$ supplementation (Figure 6). The interim serum $\mathrm{Mg}$ was subnormal (less than $0.7 \mathrm{mmol} / \mathrm{l}$ ) in 21 episodes. Magnesium replacement was administered in 12/21 (57.1\%). Serum Mg was measured prior to I5/43 (35\%) of the administered cycles.

\section{DISCUSSION}

Cisplatin is an effective component of the ESHAP regimen. The most common side effects associated with this agent include nausea and vomiting, nephrotoxicity

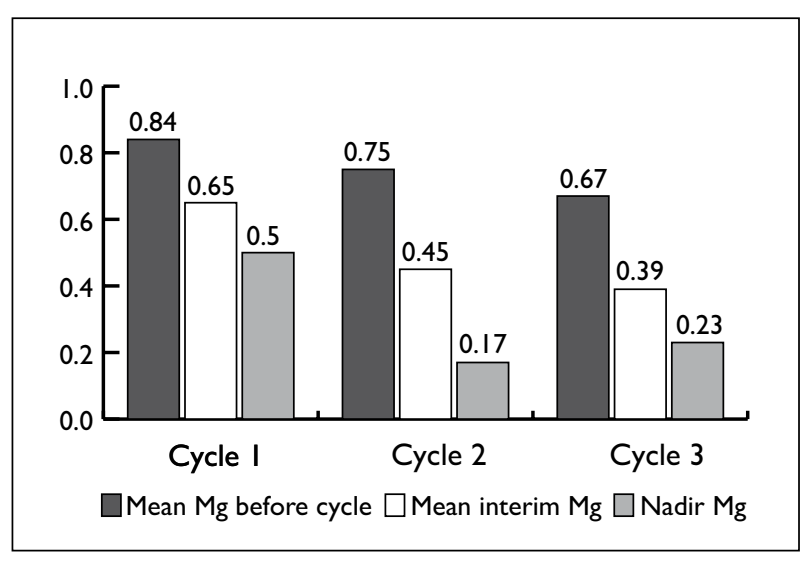

FIGURE 5 Pre-treatment, interim and nadir Mg levels (mmol/l)

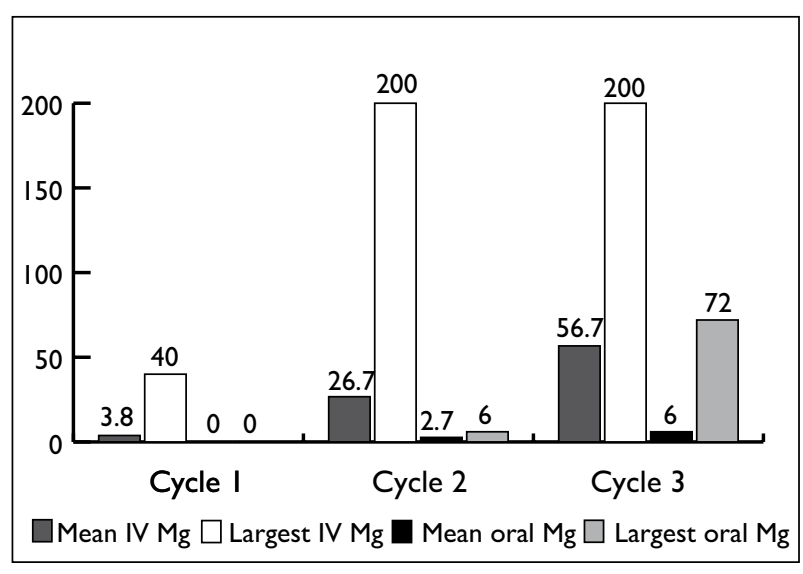

FIGURE 6 Administered $\mathrm{Mg}$ supplementation (mmol) after each ESHAP cycle

(glomerular and tubular), ototoxicity, neuropathy and myelosuppression. The nephrotoxicity of cisplatin almost led to its abandonment, until research proved that diuresis and aggressive hydration significantly ameliorated the development of renal failure. ${ }^{7.8}$

Proposed mechanisms for cisplatin renal toxicity range from definitive histological changes found in the proximal convoluted tubules to physiological and biochemical alterations involving a decrease in mitochondrial respiratory function, enzymatic activity in the respiratory chain and glutathione peroxidase and effects on cellular calcium homeostasis. ${ }^{9,10}$ Our retrospective review was conducted in an audit format to address the primary questions related to electrolytes changes and the practice of electrolyte monitoring. We did not collect data that would enable us to formally assess kidney function.

In cisplatin-treated patients creatinine clearance, a measure of kidney function, decreases as serum creatinine increases." There is evidence that renal cortical platinum accumulation is significantly associated with increase in serum creatinine. ${ }^{12}$ The mean serum creatinine values were stable and well within the normal range throughout the audit period (Table I). This may be explained by 
patients receiving adequate hydration. On days $\mathrm{I}-5$, etoposide was administered as an intravenous infusion in $500 \mathrm{ml} 0.9 \%$ normal saline (N/Sal) over one hour, methylprednisolone in $100 \mathrm{ml} \mathrm{N} / \mathrm{Sal}$ over 30 minutes and cisplatin in I,000 ml N/Sal over II hours. Concurrently, $2,000 \mathrm{ml} \mathrm{N} / \mathrm{Sal}$ was infused over 22 hours.

The small sample size, lack of detailed renal function studies and non-randomised nature of this observational report precludes firm conclusions on the role and impact of drug-induced renal injury.

While a renal injury following cisplatin doses such as those used in this sample would be predicted, we could not characterise the impact of this on renal function in detail due to the retrospective nature of the observations and design of this study.

In a study of 35 adult patients who exhibited profound hypomagnesaemia, hypokalaemia, and hypocalcaemia on their admission, the most common causes of the syndrome were alcoholism and cisplatin administration. ${ }^{4}$

Overall, in our series serum $\mathrm{K}$ and $\mathrm{Ca}$ levels showed only minimum changes after cisplatin administration. Magnesium plays an important role in the maintenance of intracellular $\mathrm{K}$. Concomitant $\mathrm{Mg}$ deficiency in K-depleted patients ranged from $38 \%$ to $42 \%$. In one of our patients, and as also shown in previous reports in the literature, hypokalaemia was severe and refractory when preceded by hypomagnesaemia. ${ }^{13} \mathrm{It}$ is recommended that serum $\mathrm{Mg}$ is routinely assessed, and that until serum $\mathrm{Mg}$ is measured consideration should be given to treating hypokalaemic patients with both $\mathrm{Mg}$ and $\mathrm{K} .^{14}$

There are some reports in the literature of hypokalaemia in cisplatin-treated patients, and in some reports it has been associated with paralysis. ${ }^{15}$ Glucocorticoids, including methylprednisolone, can cause hypokalaemia. It is interesting that our patients showed only minimal changes in $\mathrm{K}$ serum levels. One explanation is the routine and frequent measurement of serum $\mathrm{K}(100 \%$ in our patients), which may have led to the detection of early minor serum $K$ changes that were effectively managed early with low doses of $K$ supplements. The second explanation is that the study was not powered to detect important differences.

Hypocalcaemia is a recognised phenomenon in cisplatintreated patients. However, it is not as common as changes in $\mathrm{Mg}$ levels. In a prospective study of 17 patients receiving chemotherapy with cisplatin, hypomagnesaemia was found in $53 \%$ to $88 \%$ of patients, depending on the definition of hypomagnesaemia. Hypocalcaemia occurred in only one patient $(5.8 \%){ }^{16} \mathrm{In}$ a study of $\mathrm{K}$ and $\mathrm{Mg}$ metabolism after repeated cisplatin treatments in rats it was found that cisplatin treatment exerted a negative effect on total $\mathrm{K}$ balance, although the difference between cisplatin-treated and control rats was not significant at the end of the follow-up. ${ }^{3}$

Serum $\mathrm{Mg}$ levels showed an obvious and progressive decline in our patients. This finding is supported by similar reports in the literature. Hypomagnesaemia in cisplatin-treated patients was reported with or without renal failure. Gomez Campdera et al. reported a 15-yearold female who developed acute renal failure following two courses of cisplatin. The main features were symptomatic hypomagnesaemia, hypocalcaemia and hypokalaemia, which were adjusted after administering intravenous magnesium. Renal failure persisted for several months. ${ }^{77}$ Other patient series report hypomagnesaemia in up to $88 \%$ of patients receiving cisplatin. ${ }^{14,18,19}$ Hypomagnesaemia can be life-threatening; for example, Bashir et al. report a patient with cisplatininduced hypomagnesaemia who suffered brief asystole. ${ }^{20}$

The degree of hypomagnesaemia is related to the cumulative cisplatin dose. The incidence following cisplatin $50 \mathrm{mg} / \mathrm{m}^{2}$ in combination with vincristine, cyclophosphamide, lomustine and doxorubicin for the treatment of lung cancer was $41 \%$ (II of 27 patients) after the first cycle, $86 \%$ ( 12 of I 4 patients) after the fifth cycle and $100 \%$ (two of two patients) following the sixth cycle of chemotherapy. ${ }^{21}$ Our results also show the cumulative effect of cisplatin on serum magnesium level. In our patients the baseline, interim and nadir levels showed progressive decline and the amount of magnesium supplementation progressively increased.

Hypomagnesaemia can result from decreased intake (starvation, alcoholism and prolonged postoperative state), decreased gastrointestinal absorption, diarrhoea and increased urinary losses. Severe deficiency usually requires a combination of these factors. ${ }^{22}$ Persistent vomiting may contribute to $\mathrm{Mg}$ deficiency. In this retrospective sample we did not document accurate data on the prevalence or severity of vomiting. Severe and/or persistent chemotherapy-induced vomiting is less common with the regular use of effective modern antiemetic drugs. Our patients received $3 \mathrm{mg}$ of intravenous granisetron daily prior to starting chemotherapy on days $\mathrm{I}-5$. On discharge they were instructed to use $4 \mathrm{mg}$ oral dexamethasone twice a day regularly for two days and 10-20 mg domperidone every six hours if they felt nauseous. On this principle we believe it is unlikely that short-term chemotherapy-induced vomiting generated significant $\mathrm{Mg}$ depletion in this sample of patients.

Cisplatin is the cytotoxic drug most commonly implicated in electrolyte imbalance. However, caution is needed in interpreting the cause of these imbalances, especially when using multi-drug chemotherapy regimens, diuretics, antimicrobials and other nephrotoxic drugs. Our patients received other cytotoxic agents (in ESHAP), although these are not known to significantly affect serum 
electrolyte levels. The effect of systemic short pulses of high-dose steroids on serum $\mathrm{Mg}$ is not well defined. Data on longer-term use at smaller doses are conflicting. In renal transplant patients on steroids and other immunosuppressive therapies, cyclosporine but not steroids or azathioprine was associated with hypomagnesaemia. ${ }^{23}$ In patients with chronic obstructive airway diseases, a significant negative correlation between serum $\mathrm{Mg}$ and the length (24 months) of oral steroid therapy was observed. ${ }^{24}$ Diuretic use was infrequent and kidney function was satisfactory. This suggests that the electrolyte change in our patients was highly likely to be due to cisplatin. While intravenous (IV) Mg replacement was used, the net impact on renal clearance (loss) of $\mathrm{Mg}$ was not documented.

The standard replacement treatment of hypomagnesaemia is via the IV route. We primarily used IV $\mathrm{Mg}$ replacement. Oral $\mathrm{Mg}$ glycerophosphate was used in cases of mild hypomagnesaemia and as short-term maintenance after IV supplementation (unlicensed indication but widely accepted).

We did not investigate the mechanism of $\mathrm{Mg}$ loss in our patients. However, it is now thought that $\mathrm{Mg}$ loss associated with cisplatin treatment is mainly the result of lowered intestinal absorption and not, as previously suspected, of increased renal elimination. Lajer et al. investigated changes in renal and intestinal homeostasis of $\mathrm{Mg}$ and $\mathrm{K}$ during repeated cisplatin treatments in rats. ${ }^{3}$ Cisplatin exerted a significant negative effect on total $\mathrm{Mg}$ balance. This effect was cumulative. The observed difference was mainly due to the difference in $\mathrm{Mg}$ balance between the treatment day and the following two to three days. The urinary excretion of $\mathrm{Mg}$ did not differ significantly between the two groups at the end of the follow-up. A significant decrease was observed in intestinal absorption in treated rats compared with control rats at the end of the follow-up. Lowered intestinal absorption accounted for $90 \%$ of the difference in total $\mathrm{Mg}$ balance between the two groups as compared to renal loss. ${ }^{3}$ The authors suggest that $\mathrm{Mg}$ metabolism is subject to predictable changes and that knowledge of these changes can be used in planning supplementation. Thus, the experimental observations support IV supplementation on the day of treatment and two to three days after treatment, followed by oral supplementation. Other possible prophylactic measures include the use of nephro-protectants such as amifostine..$^{25}$

\section{CONCLUSION}

This evaluation shows that hypokalaemia and hypocalcaemia are uncommon but recognised in patients receiving ESHAP. Hypokalaemia can be symptomatic and require prolonged admission, especially if associated with hypomagnesaemia. Physicians are aware of the importance of measuring serum $\mathrm{K}$ in these patients. However, hypomagnesaemia is a progressive complication of cisplatin administration and physicians need be aware of its importance and that of measuring serum $\mathrm{Mg}$.

\section{REFERENCES}

I Choi CW, Paek CW, Seo JH et al. ESHAP salvage therapy for relapsed or refractory non-Hodgkin's lymphoma.J Korean Med Sci 2002; 17:62|-4.

2 Velasquez WS, McLaughlin P, Tucker S et al. ESHAP - an effective chemotherapy regimen in refractory and relapsing lymphoma: a 4-year follow-up study. J Clin Oncol 1994; 12:2766-70.

3 Lajer $\mathrm{H}$, Kristensen $\mathrm{M}$, Hansen $\mathrm{HH}$ et al. Magnesium and potassium homeostasis during cisplatin treatment. Cancer Chemother Pharmacol 2005; 55:23I-6. doi:10.1007/s00280-004-0899-6

4 Elisaf $M$, Milionis $H$, Siamopoulos KC. Hypomagnesemic hypokalemia and hypocalcemia: clinical and laboratory characteristics. Miner Electrolyte Metab 1997; 23:105-12.

5 Hoffmann K, Marten A, Lindel K et al. Major combined electrolyte deficiency during therapy with low-dose cisplatin, 5-fluorouracil and interferon alpha: report on several cases and review of the literature [ISRCTN62866759]. BMC Cancer 2006; 6:128. doi: I0.I I86/| 47|-2407-6-128

6 Schilsky RL. Renal and metabolic toxicities of cancer chemotherapy. Semin Oncol 1982; 9:75-83.

7 Cvitkovic E, Spaulding J, Bethune $\mathrm{V}$ et al. Improvement of cisdichlorodiammineplatinum (NSC I 19875): therapeutic index in an animal model. Cancer I977; 39:|357-6I. doi:10.1002/10970।42(I 97704)39:4<| 357::AID-CNCR2820390402>3.0.CO;2-C

8 Hayes D, Cvitkovic E, Golbey R et al. High dose cis-platinum diamine dichloride: amelioration of renal toxicity by mannitol diuresis. Cancer 1977; 39:1372. doi:I0.1002/1097-0|42(I97704)39:4<1372::AIDCNCR2820390404>3.0.CO;2-J

9 Anand AJ, Bashey B. Newer insights into cisplatin nephrotoxicity. Ann Pharmacother 1993; 27:1519-25.

10 Wolfgang GH, Dominick MA, Walsh KM et al. Comparative nephrotoxicity of a novel platinum compound, cisplatin, and carboplatin in male Wistar rats. Fundam Appl Toxicol 1994; 22:73-9. doi:I0.1006/faat.1994.1010

II Dentino M, Luft FC, Yum MN et al. Long term effect of cisdiamminedichloride platinum (CDDP) on renal function and structure in man. Cancer 1978; 4I:I274-8I. doi:10.1002/10970|42(I97804)4I:4<|274::AID-CNCR28204I04 I0>3.0.CO;2-F

12 Stewart DJ, Mikhael NZ, Nanji AA et al. Renal and hepatic concentrations of platinum: relationship to cisplatin time, dose, and nephrotoxicity. J Clin Oncol 1985; 3:125I-6.

13 Rodriguez M, Solanki DL,Whang R. Refractory potassium repletion due to cisplatin-induced magnesium depletion. Arch Intern Med I989; |49:2592-4. doi:10.1001/archinte. I49.1 I.2592

14 Whang R, Whang DD, Ryan MP. Refractory potassium repletion. A consequence of magnesium deficiency. Arch Intern Med 1992; I52:40-5. doi: 10.1001/archinte.152.1.40 
I5 Mohammadianpanah M, Omidvari S, Mosalaei A et al. Cisplatininduced hypokalemic paralysis. Clin Ther 2004; 26:1320-3. doi:10.1016/S0149-2918(04)80177-2

16 Stewart AF, Keating T, Schwartz PE. Magnesium homeostasis following chemotherapy with cisplatin: a prospective study. Am J Obstet Gynecol 1985; 153:660-5.

17 Gomez Campdera FJ, Gonzalez P, Carrillo A et al. Cisplatin nephrotoxicity: symptomatic hypomagnesemia and renal failure. Int J Pediatr Nephrol 1986; 7:I5I-2.

18 Ariceta G, Rodriguez-Soriano J,Vallo A et al. Acute and chronic effects of cisplatin therapy on renal magnesium homeostasis. Med Pediatr Oncol 1997; 28:35-40. doi:I0.1002/(SICI) I096-9| IX(I9970I)28: I<35::AIDMPO7>3.0.CO;2-U

19 Ashraf M, Scotchel PL, Krall JM et al. Cis-platinum-induced hypomagnesemia and peripheral neuropathy. Gynecol Oncol 1983; 16:309-18. doi:10.1016/0090-8258(83)90156-7

20 Bashir $H$, Crom D, Metzger $M$ et al. Cisplatin-induced hypomagnesemia and cardiac dysrhythmia. Pediatr Blood Cancer 2007; 49:867-9. doi:10.1002/pbc.20804
2I Buckley JE, Clark VL, Meyer TJ et al. Hypomagnesemia after cisplatin combination chemotherapy. Arch Intern Med 1984; | 44:2347-8. doi: 10.100 I/archinte. I 44. I 2.2347

22 Moe SM. Disorders involving calcium, phosphorus, and magnesium. Prim Care 2008; 35:2I5-37. doi:10.1016/j.pop.2008.01.007

23 Barton $\mathrm{CH}$, Vaziri ND, Martin DC et al. Hypomagnesemia and renal magnesium wasting in renal transplant recipients receiving cyclosporine. Am J Med 1987; 83:693-9. doi:10.1016/00029343(87)90900-4

24 Rolla G, Bucca C, Bugiani M et al. Hypomagnesemia in chronic obstructive lung disease: effect of therapy. Magnes Trace Elem 1990; 9:132-6.

25 Hartmann JT, Fels LM, Knop S et al. A randomized trial comparing the nephrotoxicity of cisplatin/ifosfamide-based combination chemotherapy with or without amifostine in patients with solid tumors. Invest New Drugs 2000; I8:28I-9. doi: I0.1023/A:I006490226I04

\section{INVITATION TO SUBMIT PAPERS}

We would like to extend an invitation to all readers of The Journal of the Royal College of Physicians of Edinburgh to contribute original material, especially to the clinical section. The JRCPE is a peer-reviewed journal with a circulation of 8,000 . Its aim is to publish a range of clinical, educational and historical material of cross-specialty interest to the College's international membership.

The JRCPE is currently indexed in Embase, Google Scholar and the Directory of Open Access Journals, and the History section is included in Medline. The editorial team is keen to continue to improve both the quality of content and its relevance to clinical practice for Fellows and Members.

All papers are subject to peer review and our turnaround time for a decision averages only eight weeks.

We would be pleased to consider submissions based on original clinical research, including pilot studies. The JRCPE is a particularly good forum for research performed by junior doctors under consultant supervision. We would also consider clinical audits where the loop has been closed' and a demonstrable clinical benefit has resulted.

For further information about submissions, please visit: http://www.rcpe.ac.uk/journal/contributers.php or e-mail editorial@rcpe.ac.uk

Thank you for your interest in the College's journal.

The editorial team,

The Journal of the Royal College of Physicians of Edinburgh

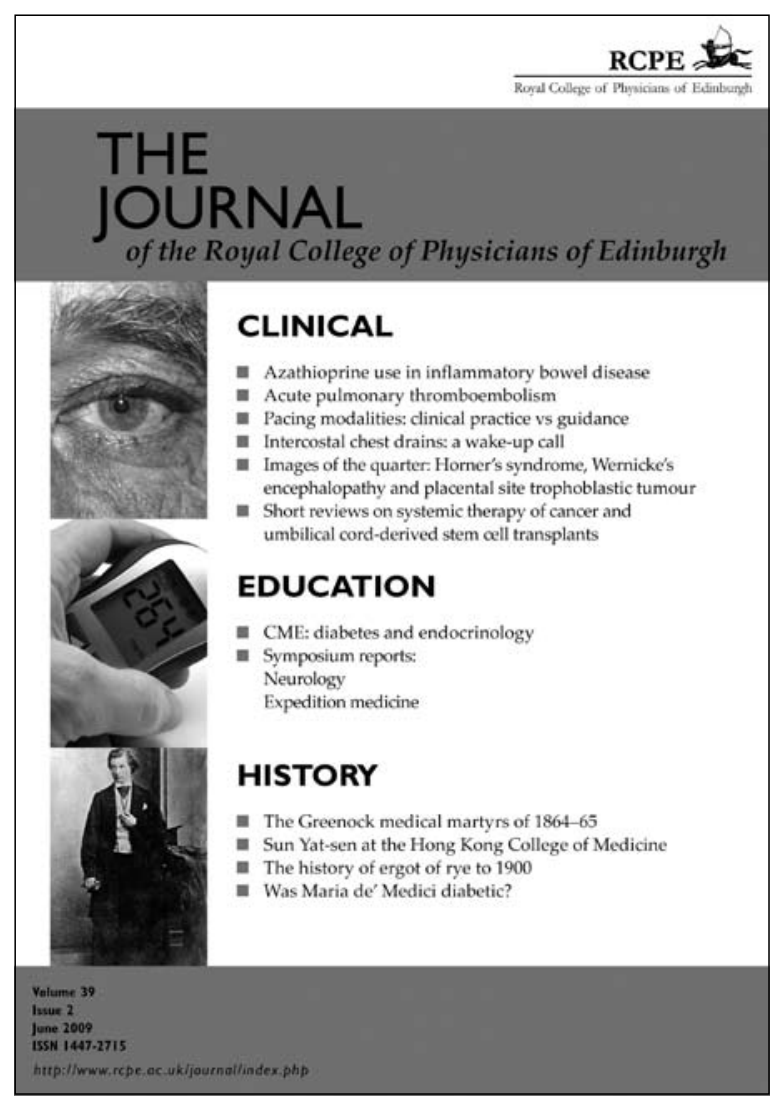

- Azathioprine use in inflammatory bowel disease thromboembolism thert reviews on systemic therapy of cancer and EDUCATION

- CME: diabetes and endocrinolog Symposium report:

\section{HISTORY}

- The Greenock m Sun Yat-sen at the Hong Kong College of Medicin The history of ergot of rye to 1900 Was Maria de' Medici diabetic? 